\title{
Aproximaciones al concepto de Discurso Profesional Docente
}

\section{Marco Antonio Alarcón*}

\section{Resumen}

El presente artículo pretende instalar el concepto de "Discurso Profesional Docente" para referirse a las prácticas discursivas emanadas en el desempeño de las funciones que implica la labor profesional docente. Para lograr este objetivo, se revisan dos tipos de aproximaciones: la primera sobre el concepto de "Discurso Profesional" y la segunda sobre la "Profesión Docente" y las funciones que ella implica. En la discusión, se apunta a la conceptualización del "Discurso Profesional" y a las funciones de la "Profesión Docente" para delimitar y definir el concepto de "Discurso Profesional Docente". Finalmente, en la conclusión se recoge una síntesis de los aportes considerados en esta propuesta conceptual y se señalan además algunas implicancias para futuros desarrollos investigativos.

Palabras clave: Discurso Profesional, Profesión Docente, Discurso Profesional Docente.

\section{Approaches to the concept of Professional Teaching Discourse}

\begin{abstract}
This article intends to establish the "professional teaching discourse" as the concept encompassing discursive practices that come from perfomance functions that professional teaching work involves. For this purpose, two approaches are examined: the first idea deals with the concept of "professional discourse"; the second term refers to teaching profession and related functions. The discussion aims at the conceptualization of "professional discourse" and the functions of teaching work with a view to defining the concept of "professional teaching discourse". Finally, the conclusion presents a synthesis of the contributions to this conceptual proposal and some implications for further research are discussed.
\end{abstract}

Key words: professional discourse, teaching discourse, professional teaching discourse.

* Magíster en Lingüística. Doctorando en Lingüística de la Pontificia Universidad Católica de Chile. Académico Universidad Católica Silva Henríquez.malarcon@ucsh.cl, maalarcon@uc.cl 


\section{Introducción}

Desde la lingüística de sistema, los estudios de terminología o de lenguas especializadas que han abordado en forma específica o global algún aspecto de la investigación educativa, lo han hecho en un sentido más bien léxico y/o conceptual. Así, el producto de dicha labor ha sido la producción de diccionarios terminológicos de Pedagogía y/o Educación.

No existe un planteamiento desde la Lingüística del uso, en términos del establecimiento de un Discurso Profesional Docente que dé cuenta de las prácticas discursivas generadas en el desempeño de las funciones que implica la labor profesional docente.

El presente artículo pretende instalar una primera aproximación al concepto de Discurso Profesional Docente a partir de la revisión de los conceptos de Discurso Profesional y Profesión Docente. Esto implica considerar las diversas funciones de esta profesión, sus relaciones discursivas profesionales con el Estado y los tipos de discurso especializado que la constituyen, tanto en ejercicio, como en la formación profesional.

La revisión teórica presenta algunas aproximaciones al Discurso Profesional y a los alcances discursivos de la Profesión Docente, para luego de la discusión configurar el concepto de Discurso Profesional Docente.

En la conclusión se sintetizan los aportes considerados en la revisión teórica y en la discusión, y se señalan algunas implicancias para futuros desarrollos investigativos.

\section{Marco Teórico}

El objetivo de este marco teórico es dar cuenta de una revisión bibliográfica primero del concepto Discurso Profesional y, luego, de la Profesión Docente considerando los aspectos discursivos implicados en ella, la relación con el Estado y las funciones de la labor docente.

\subsection{Discurso Profesional}

La perspectiva evolutiva desde la lingüística del sistema a la lingüística del uso, tiene su correlato en el estudio desde las lenguas con fines especificos a los discursos profesionales, como lo plantea López (2002: 196):

Las reflexiones en torno a los textos que se producen en el ejercicio de actividades específicas han ido evolucionando a la par que los estudios sobre la lengua y su uso. 
López (2002) agrega que la evolución del estudio de la investigación lingüística ha transitado desde "la descripción de la lengua como sistema abstracto al análisis del uso lingüístico en contexto" (López, 2002: 197) cuyos avances se reflejan en:

El camino recorrido desde el estudio de los lenguajes con fines específicos, las lenguas especiales o especializadas, los textos específicos, los discursos de especialidad y académicos hasta los discursos profesionales (López, 2002: 196).

López (2002) afirma que, en los estudios más recientes sobre uso de la lengua en contextos específicos, se ha utilizado la etiqueta Discurso Profesional dejando atrás la denominación de lenguajes con fines específicos. Dicho cambio de denominación da cuenta de un nuevo enfoque con otro tipo de análisis para estudiar lingüísticamente los textos específicos.

Para López (2002), la perspectiva de la lengua como sistema acentuaba el análisis de los aspectos terminológicos y estilísticos, focalizándose en rasgos léxicos específicos de los discursos. La perspectiva actual parte "desde la década de los 80, hacia el estudio de las estructuras supraoracionales y textuales (...) "y hacia el análisis de su función entre profesionales o académicos, tanto desde el punto de vista social como cognitivo" (López, 2002: 198).

López (2002) señala que la evolución de la descripción de los discursos científicos es un modelo sobre cómo se ha abordado en distintas décadas el análisis de textos específicos. No obstante, agrega que:

el ámbito de los discursos profesionales es de tal complejidad que la historia de su constitución y del estudio del uso de la lengua en cada una de las profesiones presenta diferencias notables (López, 2002: 197).

Desde la perspectiva de los discursos científicos Gunnarson (1998: 38) sostiene que:

Language constructs science in relation to the cognitive layer (the scientific content), the societal layer (the scientists' role in society) and the social layer (relations within the group). This construction process has been in progress since the first doctors tried to establish themselves as medical scientists and it is still continuing.

Es decir, la lengua construye la ciencia a través de la articulación de un contenido científico, su rol científico en la sociedad y las relaciones 
sociales al interior de una determinada comunidad científica. Tal proceso ha permitido que, por ejemplo, la medicina se haya constituido como ciencia y lo siga haciendo.

López (2002) define los Discursos Profesionales de la siguiente forma:

Al hablar de discursos profesionales ponemos énfasis en la incidencia del contexto en la configuración textual, en el papel que desempeñan estos discursos entre los miembros de una comunidad profesional, entre estos profesionales y la sociedad, y en la acción de "profesar" que ejercen (López, 2002: 198).

Acentúa el rol interactivo de los textos tanto entre una comunidad profesional, como entre ésta y la sociedad, a través de la movilización de conocimientos especializados y de la labor ejercida en determinada profesión por medio de los textos.

Con respecto a la distinción entre discurso profesional y discurso especializado, López (2002) sostiene que el Discurso Profesional considera no sólo el análisis de discursos que vehiculan conocimiento de especialidad, sino que incluye, además, los textos producidos en el ejercicio de un oficio, no siendo la especialización un aspecto caracterizador de este tipo de discurso.

Para Cabré (2000), el foco está en la situación comunicativa especializada de una profesión, a través de la cual se transmite un conocimiento:

Un simple análisis de la comunicación especializada que se produce en situaciones profesionales de distinto signo muestra una multiplicidad importante de registros, sin que ello suponga abandonar el carácter especializado del conocimiento y su transmisión, y pone de manifiesto una serie de características coincidentes con las unidades utilizadas en otros tipos de situaciones comunicativas (2000: 129-130).

Para Lerat (1997: 17), "La noción de lengua especializada es mucho más pragmática: es la lengua natural considerada como instrumento de transmisión de conocimientos especializados", es decir, este autor focaliza la transmisión de conocimientos especializados, pero no "los conocimientos especializados en sí mismos", sino como él mismo sostiene:

Una lengua especializada no se reduce a una terminología: utiliza las denominaciones especializadas (términos) y tam- 
bién los símbolos no lingüísticos en enunciados que utilizan los recursos ordinarios de una lengua concreta. Por lo que se puede definir como el uso de una lengua natural para exponer técnicamente los conocimientos especializados" (Lerat, 1997: 18).

Es decir, para Lerat, una lengua especializada no se reduce al conocimiento especializado, sino que incluye aspectos no lingüísticos y recursos propios de la lengua en que se constituye la lengua especializada, la cual es utilizada en una situación profesional como el mismo Lerat (1997: 18) agrega:

La lengua especializada es, ante todo, una lengua en situación de empleo profesional, es decir, una "lengua en especialidad" como dice la escuela de Praga. Es la lengua misma como sistema autónomo, pero al servicio de una función más amplia: la transmisión de conocimientos (...) Los conocimientos especializados disponen de denominación lingüística gracias a los términos, que son generalmente palabras y grupos de palabras (nominales, adjetivos, verbales, etc.) sometidos a definiciones convencionales (Lerat, 1997: 18).

Desde la perspectiva de los textos técnicos, también es posible alguna aproximación al concepto de "Discurso Profesional" como plantea Gamero (2001: 38):

proponemos definir el texto técnico como un acto concreto de comunicación en el que los emisores son ingenieros, técnicos o profesionales; los receptores son otros ingenieros, técnicos, especialistas en formación o público en general; la situación comunicativa está relacionada con la industria, la explotación agrícola, la fabricación de productos o la oferta de servicios; el foco predominante es la exposición o la exhortación; el modo es generalmente escrito; el campo es de carácter exclusivamente técnico...

En esta definición de texto técnico, está presente también la idea de situación comunicativa y se focaliza su uso como texto técnico en la comunicación profesional entre expertos, entre un experto y especialistas en formación y entre expertos y público en general sin experticia.

El propio Gamero (2001) plantea la idea de los géneros técnicos y las modalidades de presentación de estos que se constituyen con relación a convenciones. 
Cada uno de los géneros técnicos presenta una serie de elementos textuales fijos: uno o dos focos contextuales (exhortativo, expositivo, o ambos combinados), un emisor que es siempre un especialista, un receptor que puede ser otro especialista o bien el público general, un modo que puede ser escrito, oral o audiovisual, y, finalmente, y en tanto que prototipo, un funcionamiento textual interno de características relativamente fijas y convencionales (Gamero, 2001: 61-62)

Desde la perspectiva de los textos comerciales Álvarez (1997) acentúa también la idea de interacción entre un conocimiento general y convencional. Además, da cuenta de que los textos, en particular los escritos, hacen funcionar las relaciones laborales en una empresa y en la sociedad.

Los textos comerciales poseen una serie de propiedades que adquieren su efectividad en la medida en que existe un conocimiento general y convencional interactivo. Se ponen en funcionamiento a través de estos escritos relaciones laborales de suma importancia para la empresa en particular o para la sociedad en sentido amplio. Esto significa que la mayor parte de los que se dedican a estas actividades tienen que conocer esas convenciones y además saber aplicarlas adecuadamente (Álvarez, 1997: 13).

El Discurso Profesional también ha sido considerado con relación a sus aspectos sociales como realidad discursiva, tal como lo caracteriza Moirand (1994: 82):

los discursos profesionales se caracterizan por presentar un número importante de elementos de naturaleza sociolingüística y por un mayor juego enunciativo dado que el locutor se manifiesta de múltiples maneras, generando así un discurso más personalizado o, si se quiere, más humano [...] "Las múltiples disciplinas profesionales, sus distintos usos, las diversas particularidades enunciativas que ofrecen, el nivel de conocimientos del que enuncia, la variada tipología de los receptores, el lugar en que se puede producir la comunicación así como los incalculables elementos sociolingüísticos y culturales que condicionan el enunciado profesional influyen decisivamente en la realidad discursiva resultante.

Es decir, los discursos profesionales presentan características sociolingüísticas en función de la diversidad de las profesiones y de los 
receptores con los cuales interactúa un profesional en el desempeño de su labor, sin dejar de lado el nivel de los conocimientos especializados del profesional experto.

Desde un sentido menos especializado y mucho más social, un Discurso Profesional también puede incluir los términos no normativos que se producen en la interacción dentro de un oficio y que poseen una evidente naturaleza sociolingüística, como señalan Charaudeau y Maingueneau (2005: 45) con relación a los argots de oficio considerados como:

los vocabularios creados en el trabajo [para los cuales] se dispone de varios términos como "vocabularios de oficio, jergas, argots". Aunque no sean enteramente sustituibles entre sí, remiten al mismo fenómeno sociolingüístico: la profusión de creación léxica en el medio profesional (Boulet, 2001). Este hecho fue percibido hace largo tiempo y ya en el siglo XIX aparecieron recopilaciones de vocabularios profesionales (Boutmy, 1883). Esta actividad de denominación alcanza al conjunto del entorno del trabajo: a las personas, a las actividades productivas, a los objetos de la actividad.

En otro sentido, focalizados en las instituciones en que se labora, se plantean los estudios de comunicación en la organización, los cuales se relacionarían también con el "Discurso Profesional". Desde esta perspectiva Mumby y Clair (2000: 263) sostienen que el estudio de la comunicación organizacional consiste en: "[c]onocer el modo cómo las personas realizan, mediante el discurso, la tarea cotidiana de funcionar como parte de estructuras grandes, coordinadas e institucionalizadas", es decir, el discurso permite desarrollar las funciones laborales dentro de una organización.

En esta misma perspectiva anterior se plantean Drew y Sorjonen (2000: 141-142) desde el estudio del diálogo institucional entendido en los siguientes términos:

El estudio del "diálogo institucional" es, entonces, el estudio del modo como las personas utilizan el lenguaje para conducir esas tareas prácticas y desempeñar las actividades particulares asociadas con su participación en contextos institucionales, tales como enseñar, describir síntomas, interrogar, hacer averiguaciones, negociar y entrevistar.

En otras palabras, son las interacciones lingüísticas las que permiten desarrollar las labores dentro de un contexto institucional. 
En una perspectiva algo similar a las dos anteriores, Cassany (2004) plantea un concepto de organización en el cual se considera la interacción verbal como actividad base para conseguir ciertos propósitos dentro de una organización. La propuesta de Cassany parte de la detección de cuatro perspectivas desde las que han sido estudiados los discursos especializados, a saber:

1. Orientación lingüística (análisis del discurso, terminología, lingüística aplicada),

2. Político-sociológica (teoría de la organización)

3. Desarrollo empresarial (búsqueda de la calidad, mejora de resultados, formación, etc.)

4. Enseñanza del español (cursos de español comercial, para empresarios, para relaciones internacionales, etc.) (Cassany, 2004: 49).

Cassany (2004) sostiene que no ha habido interrelación entre estas áreas de investigación. Por ello, su propuesta es romper el aislamiento. En ese contexto, plantea su concepto de organización:

Entendemos la organización como una agrupación estructurada de personas que desarrollan actividades específicas para conseguir propósitos que no podrían alcanzarse individualmente; la interacción verbal entre estos individuos es uno de los elementos constitutivos de la organización y una de sus herramientas para conseguir los objetivos (2004:49)

Esta perspectiva organizacional le permite redefinir, por ejemplo, algunos conceptos como español de los negocios:

El español de los negocios es la lengua utilizada en los discursos generados en las organizaciones de la comunidad hispanohablante. Preferimos hablar de discursos de las organizaciones que de español de negocios porque las comunicaciones se materializan en forma de textos orales y escritos y porque se contextualizan en organizaciones particulares -que suelen tener una cultura, unos géneros y un estilo también particulares (Cassany, 2004: 49-50).

Cassany (2004) elabora una estructura de análisis de los discursos de una organización y propone incluso, a partir de una evaluación de los discursos que operan dentro de una institución, una reestructuración discursiva, la cual sería desarrollada por un lingüista que intervendría las organizaciones. En su propuesta confluyen variados textos que apuntan a objetivos, funciones, emisores y características diversas. 
La propuesta de Cassany llega a ser tan amplia que cualquier texto puede ser considerado parte de una organización, lo cual desdibuja cualquier parámetro tipologizador, impidiendo justamente lo que promueve, una articulación discursiva desde las organizaciones.

\subsection{Profesión Docente}

\subsubsection{Discurso Docente}

Bernstein (1997: 189) plantea la idea de discurso pedagógico como:

un principio para apropiarse de otros discursos y ponerlos en una relación especial mutua a efectos de su transmisión y adquisición selectivas [...] [ Tal postulado ] es un principio que extrae (descoloca) un discurso de su práctica y contexto sustantivos y lo recoloca según su propio principio selectivo de reordenación y enfoque. En este proceso de descolocación y recolocación del discurso original se elimina la base social de su práctica, incluidas sus relaciones de poder.

Es decir, el discurso pedagógico no posee un discurso propio, sino que refiere a discursos de especialidad que son seleccionados, reordenados y reenfocados por el Discurso Pedagógico para ser transferidos.

De manera que para Bernstein (1997: 189) este principio

[e]s un principio recontextualizador que se apropia de, recoloca, reenfoca y relaciona selectivamente otros discursos para construir su propio orden y sus propios ordenamientos. En este sentido, el discurso pedagógico no puede identificarse con ninguno de los discursos que recontextualiza. Carece de discurso en sí mismo que no sea el discurso recontextualizador.

Es decir, el discurso pedagógico se construye al reordenar y reenfocar los discursos de especialidad que utiliza para sus fines de transferencia de conocimiento, por lo cual la característica del Discurso Pedagógico es la recontextualización de otros discursos especializados.

Desde la perspectiva de los textos didácticos de Beaugrande y Dressler (1997: 254) se plantea que:

[1]os textos didácticos, por su lado, no van más allá del conocimiento habitual que la memoria social tiene almacenado, sino que únicamente se emplean para distribuir el conoci- 
miento establecido entre una audiencia no especializada, o en período de formación, de receptores textuales. Para cumplir con esta tarea, se requiere, obviamente, la presentación de un trasfondo de conocimientos más abundante y más explícito de lo que es costumbre en los textos científicos.

Es decir, esta definición de discurso didáctico focaliza, por un lado, los roles frente al conocimiento especializado entre emisor y receptor y, por otro, se considera la especialización del discurso, pero para ser discurso didáctico debe ser más explícito que los textos científicos.

Por otro lado, desde la perspectiva del estudio del Discurso Docente, Cabrera (2003: 7) sostiene que

[e]n el dominio de la educación [...] no se ha incorporado el componente comunicativo en forma integral, así como tampoco algunos de los principales conocimientos generados en los últimos tiempos, manteniendo un vínculo poco significativo (Cabrera, 2003: 7).

Es decir, los aspectos comunicativos no se han aplicado significativamente en la investigación educativa.

Con relación al mismo tipo de estudios de Discurso Docente, de la Cruz et al. (2000: 9) sostienen que

[e]l estudio de lo que los profesores efectivamente hacen y dicen en el desarrollo de sus clases ha sido y sigue siendo objeto de considerable atención desde diferentes marcos de investigación: etnográfico, lingüístico, pedagógico, sociológico, etc. Rockwell, 1982, Stubbs, 1983, Sánchez, Rosales, Caneda y Conde, 1994; De tezanos, Muñoz y Romero, 1983; Edwards, 1990.

No obstante, plantean que, probablemente,

una noción compartida en los diferentes estudios sea que las prácticas y discursos docentes en situación de clase, configurados en un contexto sumamente complejo y en los que intervienen diferentes dimensiones (macroeducativa, institucional, relativas a la inserción y sentido de la asignatura enseñada en el plan de estudios, de vínculo con el grupo de alumnos y su entorno sociocultural, temporal con relación al año académico, de familiaridad y dominio sobre los temas puntuales enseñados y sobre diversas estrategias didácticas, 
entre otros), configuran a su vez los aprendizajes de los alumnos (de la Cruz, et al., 2000: 10).

Es decir, más allá de las consideraciones interdisciplinarias involucradas en la investigación educativa de los discursos de profesores, el foco de atención ha estado en la labor docente referida al aprendizaje de los alumnos.

\subsubsection{Características de la profesión docente}

Según Ivanier et al. (2004), el conocimiento especializado y la autonomía profesional son dos elementos constituyentes de toda profesión. Sin embargo, la definición de la profesión docente no hace referencia a tales requisitos, ni apunta al trabajador, sino que interpela al agente mismo como qué es ser profesor.

En cuanto a la formación docente, Calvo (2001: 107) sostiene que

[1]a formación del profesorado de educación secundaria ha consistido, principalmente, en propuestas de qué enseñar y menos en cómo enseñar. La consecuencia de esta situación es vuelven a enseñar como lo hicieron con ellos.

Lo planteado por Calvo da cuenta del foco de formación docente puesto en el discurso especializado que debe trasmitir un profesor en su desempeño profesional.

Otros investigadores como de la Cruz et al. (2001) se han ocupado del discurso en clase de maestros primarios en distintos sectores socioculturales. Tales estudios han apuntado a los actos de habla planteados por Austin (1996) que son utilizados por los profesores en su función de "enseñanza-aprendizaje" con alumnos.

En un sentido más sociopolítico y particular del contexto de enseñanza, España Martínez (2001) sostiene que el discurso del profesorado ha pasado del compromiso social al de la profesionalización: "De las pedagogías pasamos a la pedagogía; del compromiso al profesionalismo como ideología tecnocrática" (Martínez, 2001: 89).

Es decir, existiría una evolución del rol docente que pudiera relacionarse con la tensión entre vocación y profesionalización de la labor docente.

Con relación a cuál debe ser el rol del educador, Freire (1969: 41) sostiene que 
[e]l papel del educador no es "llenar "al educando de "conocimientos" de orden técnico, sino que proporcionar, a través de la relación dialógica educador-educando, educandoeducador, la organización de un pensamiento correcto de ambos. [...] El mejor alumno de física o matemáticas, en el colegio como en la universidad, no es el que memorizó más fórmulas, sino el que percibió la razón de éstas.

Freire cuestiona el rol docente como mero transmisor de conocimientos especializados, el cual califica como de orden técnico, y plantea más bien una relación dialógica entre el educador y el educando en torno al conocimiento especializado.

Agrega Freire (1969: 52) una definición de educación:

La educación es comunicación, es diálogo, en la medida en que no es transferencia de saber, sino un encuentro de sujetos interlocutores que buscan la significación de los significados.

Con relación a cuál debe ser el rol del educador, Freire (1970: 62) sostiene que

[1] a tarea del educador, entonces, es la de problematizar a los educandos el contenido que los mediatiza, y no la de disertar sobre él, la de donarlo, la de extenderlo, la de entregarlo, como si se tratara de algo ya hecho, elaborado, acabado, terminado.

Es decir, el conocimiento especializado mediatiza al educador y al educando, no es un mero contenido que se transfiere desde el profesor al alumno. Por ello, para Freire (1969: 22),

[e]ducar y educarse no es extender algo desde la 'sede del saber' hacia 'la desde de la ignorancia', para 'salvar', con este 'saber postizo', a los que habitan en ésta.

Agrega Freire (1969: 52):

Por ello es que la tarea del educador no es la de quien se pone como sujeto cognoscente frente a un objeto cognoscible para, después de conocerlos, hablar de él discursivamente a sus educandos, cuyo papel es el de archivadores de sus comunicados.

Es decir, Freire cuestiona el foco de atención en un discurso pedagógico que refiere a un discurso especializado en bruto, y postula 
una mediatización frente a la mera transferencia, considerando, de esta manera, que la labor docente no debe estar en transferir un discurso especializado sino en una dialéctica entre educador y educando a partir de este discurso especializado.

\subsubsection{La relación entre el Estado y la profesión docente}

Un foco muy importante de la labor docente y su discurso apunta a la relación entre el Estado y la "Profesión Docente". Desde esta perspectiva, Ivanier et al. (2004: 27) sostienen que

[1]a profesión docente se constituyó al amparo de un Estado que, a la vez que promovía su desarrollo, ejercía un elevado nivel de control generando un vínculo totalmente dependiente. Esta particular relación condicionó desde el inicio la posibilidad de la docencia de definirse en forma autónoma como cuerpo profesional y limitó sus espacios de participación en las decisiones en torno a la orientación y los contenidos de la educación. En este escenario, el rol del docente queda fuertemente ligado a la transmisión de conocimientos, al tiempo que es desvinculado de los espacios de producción y de los de selección de los conocimientos a ser distribuidos.

Existe, entonces, una necesaria dependencia de la Profesión Docente con el Estado, la cual impidió la posibilidad de autodeterminación profesional de los docentes y la decisión sobre los contenidos de discursos especializados que involucra el ejercicio docente.

Esta relación entre el Estado y los docentes se sostiene a partir leyes que regulan la labor docente. Desde esta perspectiva, según Ivanier et al. (2004: 7),

[e]l estudio de los estatutos docentes como leyes que explicitan y objetivan relaciones de poder, analiza las concepciones en torno a lo docente y el Estado que subyacen a los mismos, así como las tensiones que han atravesado históricamente el campo de la educación, por ejemplo las que se manifiestan entre lo profesional, lo técnico y lo vocacional.

Entonces, las leyes del Estado llamadas Estatutos Docentes dan cuenta de las relaciones históricas entre el Estado y la Profesión Docente. Estos estatutos regulan el "trabajo de enseñar y comprenden entre otras cuestiones, concepciones de la docencia, su ubicación en red de relaciones de poder y garantías de derechos" (Ivanier et al., 2004: 12). 
Frente al rol profesional docente Ivanier et al., (2004: 14) sostienen que

[1] a profesionalidad del docente podría ser interpretada como un quehacer social que comprende diversos elementos como su formación, el control del proceso de enseñanza y la organización del cuerpo docente para la realización de un trabajo colectivo.

De manera que la profesionalidad docente no sólo involucra las funciones que realizan los docentes, sino que incluye la formación docente y la regulación de la institucionalidad educativa que permiten desarrollar la labor docente.

Con relación a la etapa histórica de la profesionalización de la labor educativa, desde algunos ámbitos de la investigación educativa, es considerada como una etapa ideológica de la modificación laboral docente: "La retórica del profesionalismo constituye una operación ideológica que logra afianzar la organización tecnocrática del trabajo" (Ivanier et al. 2004: 14).

Otro aspecto importante de la relación entre el rol docente y el Estado lo constituye el rol público del educador, el cual surge de la relación directa entre el docente y el Estado, como plantean Ivanier et al., (2004: 14):

La representación del docente como funcionario o servidor público da cuenta de que la legitimidad de su trabajo reside en que el Estado le ha delegado la formación institucionalizada de niños y adultos.

Esta legitimidad del rol público del educador en sus orígenes tiene una clara y fuerte impronta vocacional: "El docente, portador de una vocación de servicio, encarnaba-acríticamente- la cruzada que el estado habría impulsado". (Ivanier et al., 2004: 15).

Otro planteamiento frente a la relación Estado y labor docente es el de Giroux (1990: 175), quien propone pensar "a los profesores como intelectuales transformativos", cuestionando la idea de docente como mero transmisor de conocimientos especializados. Tal idea coincide con lo planteado por Freire $(1969,1970)$. La propuesta de Giroux (1990) apunta a esclarecer el rol que desempeñan los profesores en la producción y legitimación de los diversos intereses políticos, económicos y sociales por medio de las pedagogías que ellos mismos aprueban 
y utilizan, considerando que es una actividad humana que implica una forma de pensamiento.

Revisaremos ahora las funciones de la profesión docente.

\subsubsection{Las funciones de la profesión docente}

En Chile, la ley no 19.070 creada el 22.1.1997 y modificada el 17.11.1997, corresponde al "Estatuto de los profesionales de la educación" el cual norma los requisitos, deberes, obligaciones y derechos de carácter profesional, comunes a todos los profesionales de la educación" (Biblioteca del Congreso, 1997).

Este estatuto considera como "funciones de los profesionales de la educación las funciones docente y docente directiva, además de las diversas funciones técnico-pedagógicas de apoyo" (Biblioteca del Congreso, 1997).

Las definiciones de las funciones docentes se especifican en los artículos $6^{\circ}$ y $8^{\circ}$ de este Estatuto Docente.

Artículo $6^{\circ}$

La función docente es aquella de carácter profesional de nivel superior, que lleva a cabo directamente los procesos sistemáticos de enseñanza y educación, lo que incluye el diagnóstico, planificación, ejecución y evaluación de los mismos procesos y de las actividades educativas generales y complementarias que tienen lugar en las unidades educacionales de nivel prebásico, básico y medio.

Para los efectos de esta ley se entenderá por:

a) Docencia de aula: la acción o exposición personal directa realizada en forma continua y sistemática por el docente, inserta dentro del proceso educativo [...]

b) Actividades curriculares no lectivas: aquellas labores educativas complementarias de la función docente de aula, tales como administración de la educación; Actividades anexas o adicionales a la función docente propiamente tal; Jefatura de curso; Actividades coprogramáticas y culturales; Actividades extraescolares; Actividades vinculadas con organismos o instituciones del sector que incidan directa o indirectamente en la educación y las análogas que sean establecidas por un decreto del Ministerio de Educación. [...] 
Artículo $8^{\circ}$

Las funciones técnico pedagógicas son aquellas de carácter profesional de nivel superior que, sobre la base de una formación y experiencia docente específica para cada función, se ocupan respectivamente de los siguientes campos de apoyo o complemento de la docencia: orientación educacional y vocacional, supervisión pedagógica, planificación curricular, evaluación del aprendizaje, investigación pedagógica, coordinación de procesos de perfeccionamiento docente y otras análogas que por decreto reconozca el MINISTERIO DE EDUCACIÓN, previo informe de los organismos competentes".

(Biblioteca del Congreso, 1997)

Consideramos que los propios estatutos docentes dan cuenta de muchas más funciones que la de ser un mero transmisor de conocimientos, por tanto, la focalización exclusiva de la labor docente en la función de enseñanza, ni siquiera es la que se puede aducir a las regulaciones de un Estatuto Docente, pero no es menos cierto que las exigencias que producen el foco del rol o función de la transmisión de conocimientos especializados, emana del Estado, sino de los gobiernos que validan dichas prácticas.

Dentro de los Estatutos Docentes, no debe extrañar el rol que le compete al Estado ante las funciones de los docentes, ya que le ha delegado la formación institucionalizada de la población de su país (Ivanier et al., 2004). En otras palabras, el Estado garantiza y legitima la función docente, y he ahí el valor de los Estatutos docentes.

Cada Estatuto Docente, independiente del país de origen, considera en parte al menos seis funciones principales que desarrollan los profesores, a partir de lo cual proponemos una síntesis de las labores y/o funciones profesionales de un profesor a partir de las definiciones del ESTATUTO DOCENTE, a saber:

1. Prácticas de aula

2. Preparación, evaluación y desarrollo del proceso curricular

3. Administrativas

4. Orientación educacional y vocacional

5. Jefatura de curso

6. Labor investigativa 
La práctica de aula implica concretamente el dar o dictar clases. La preparación del proceso curricular involucra la selección de contenidos, objetivos, materiales, la evaluación y seguimiento del proceso curricular; ambas funciones comprenden una parte de la función hacer clases. La primera, es la clase en términos perceptibles, la segunda, apunta a los procesos de planificación y evaluación. Las funciones administrativas corresponden a la gestión de registros de información, pública y privada de los alumnos y sus procesos. La orientación educacional y vocacional corresponde a los procesos personales en cuanto a las dimensiones social, individual, afectiva y cognitiva de los alumnos. La jefatura de curso se centra en cómo ese sujeto es un estudiante, es decir, corresponde al seguimiento de los procesos académicos de los alumnos. La labor investigativa involucra los procesos de investigación que desarrolla un profesor al revisar, seleccionar y producir conocimientos a favor de cualquiera de sus funciones profesionales con relación al entorno de la educación y los actores ahí involucrados.

Esta rápida explicación de las funciones docentes consignadas en el Estatuto Docente da cuenta de las diversas funciones que debe desempeñar un profesor, funciones que deben ser consideradas por la investigación científica de los docentes que forman profesores en el nivel Superior o Universitario.

Tanto la investigación en educación como la formación de profesores deben cubrir cada una de las funciones especificadas en la labor docente.

La profesionalización docente debe facultar a los docentes en el desempeño de las diversas funciones que involucra la labor docente. Por ende, no debe centrarse sólo en una de las funciones que constituye el trabajo de un profesor.

\section{Metodología}

Desarrollaremos la discusión primero sobre el "Discurso Profesional" y luego discutiremos la labor de la "Profesión Docente", para luego establecer el concepto de "Discurso Profesional Docente". 


\section{Discusión}

\subsection{El Discurso Profesional}

Su origen está en las lenguas o lenguajes especializados, que corresponde a la concepción de la lingüística de sistema. Con la evolución hacia la lingüística del uso, se opta por discursos profesionales.

El foco del Discurso Profesional implica el rol de una profesión, que desarrolla un discurso científico, en el cual se constituye su discurso especializado. Forma parte de este Discurso Profesional la función o rol social de dicha profesión, y además, las relaciones al interior de una comunidad científica.

La producción de un discurso especializado desde una profesión vincula este tipo de discurso con el discurso científico y su difusión formativa en la academia en relación con el discurso académico en que se difunden estos discursos a nivel de formación profesional.

Se incluyen, además, los discursos involucrados en el desarrollo de la profesión, no necesariamente propios de la especialización, sino propios de las interacciones entre profesionales con diversos destinatarios, situaciones que dan cuenta del grado de especialidad que maneja el receptor, lo cual está supeditado al rol social de los sujetos que interactúan con el experto o profesional. Esto puede además relacionarse con los discursos didácticos que permiten transmitir de una forma menos especializada un discurso especializado que permita su difusión para un determinado destinatario.

El discurso profesional implica interacciones en situaciones comunicativas especializadas o profesionales; sin embargo, no se reduce a un discurso especializado, es decir, la especialización no determina al Discurso Profesional.

También pueden producirse argots de oficio a partir de relaciones simétricas según los roles que se establecen en la organización de sujetos dentro de una empresa.

La comunicación institucional involucra una concepción de discurso profesional más amplia enfocada a una institución empresarial, es decir, no es propio de una sola profesión, sino más bien de un sector productivo en que interactúan diversas profesiones.

De cualquier forma, cualquier intento de generalización en torno a los discurso profesionales debe ser revisado a partir de las particularidades de una profesión en sí misma. 


\subsection{La labor docente}

La profesión docente carece de discurso especializado y de autonomía profesional. El Estado define el conocimiento que se enseñará en la escuela y además, por Estatuto, rige las funciones de la labor docente. Por la misma razón, el discurso pedagógico se apropia del discurso especializado de otras disciplinas y lo reelabora desde su propio enfoque, excluyendo la base social de la práctica del discurso de origen que utiliza, de manera que no puede equipararse con ninguno de los discursos que recontextualiza. Por tanto, el Discurso Docente no es otro que el que reenfoca y utiliza.

Otras profesiones se constituyen a partir de una ciencia que elabora su propio discurso y establece las regulaciones conceptuales especializadas de su labor, situación que no ocurre con la profesión docente.

Dadas las definiciones que aporta el Estado, tanto a la selección del conocimiento especializado como a las labores y/o funciones de la profesión docente, la formación docente ha estado focalizada justamente en los contenidos del currículo que se deben enseñar y menos en cómo deben ser enseñados tales contenidos.

En cuanto a la formación docente, existe bibliografía que da cuenta de la centralidad del conocimiento especializado que debe transmitir un profesor dentro de su labor educativa en la sala de clases en el proceso de enseñanza. Y dicha formación, se enfocaría menos en cómo enseñar dichos conocimientos especializados.

El rol docente, como mero transmisor de conocimientos especializados, ha sido discutido desde los años sesenta por Freire $(1969,1970)$ planteando que "la tarea del educador [...] es la de problematizar a los educandos el contenido que los mediatiza". Desde esta perspectiva, los discursos didácticos que "se emplean para distribuir el conocimiento establecido entre una audiencia no especializada, o en período de formación, de receptores textuales" daría cuenta en parte de los requerimientos a que apunta Freire.

La educación entendida sólo como transferencia de saber corre el riesgo de centrar la labor del docente únicamente en esta función, y a la vez cercar la función de la escuela en su conjunto además. Sin embargo, no es posible negar que una de las funciones de la labor docente sea esta, pero habiendo considerado el foco del cual da cuenta Freire (1969) al plantear la tarea del docente como la de problematizar al alumno a partir del contenido que los mediatiza. 
Con relación al rol del educador como mero transmisor de conocimientos para sus alumnos, ha sido una idea ampliamente crítica y señalada como educación bancaria por Freire (1970) desde hace más de tres décadas. En dicho rol de educación bancaria, el profesor se transforma en un técnico.

La perspectiva histórica de la relación entre el Estado y la profesión docente da cuenta de una relación, que, al menos en países como Chile, Argentina y España, ha transitado desde una perspectiva en que los profesores fueron considerados como sujetos que desempeñaban una vocación o apostolado a través de su labor docente, a constituirse, a partir de los últimos procesos de Reformas Educativas desde los años noventa a la fecha, en sujetos profesionales. Esta última perspectiva ha sido señalada incluso como ideología tecnocrática.

En cuanto al desarrollo histórico, la labor docente ha transitado desde una perspectiva enfocada en la vocación o apostolado del docente, a una perspectiva de la profesionalización. Dicha perspectiva de profesionalización estaría relacionada con las Reformas Educativas implementadas a partir de la última década del siglo XX.

La legitimidad del trabajo docente reside en que el Estado ha delegado en él la formación de ciudadanos, tarea que, en los orígenes de los sistemas educativos nacionales, adquiría una fuerte impronta vocacional. El docente, portador de una vocación de servicio.

El discurso docente o pedagógico planteado como lo que los profesores efectivamente hacen se ha focalizado en la investigación de las labores desempeñadas dentro de las aulas de clases por los profesores.

La investigación pedagógica, por su parte, se ha centrado en la función prototípica de ser profesor, es decir, el dictar clases a alumnos. Las investigaciones que se han realizado desde una perspectiva lingüística moderna apuntan al ejercicio de la labor de enseñar en el aula.

Es importante considerar, además, los nuevos desafíos que representan para la labor docente la evolución de las tecnologías de la información (TICS) con relación a la concepción del profesor como transmisor de conocimientos culturales relevantes, rol que desde la INTERNET, por ejemplo, se ve seriamente amenazado, ya que la actualización de la información o conocimiento especializado al que logra acceder un alumno, puede superar ampliamente en cantidad y calidad a la recibida por el docente durante su formación profesional. 
Podemos realizar ciertos cuestionamientos a la luz de lo que hasta aquí hemos revisado, planteando por ejemplo: ¿Cuál es el rol que debe realizar un docente en el desempeño de su labor? ¿Debe atender sólo a los contenidos del programa en particular en el grado en que imparte clases? ¿Qué nivel de decisión como profesional le está permitido? ¿La función de transmisión de conocimientos es la única y prioritaria que debe ejecutar? En definitiva ¿El criterio de profesionalización del profesor debe estar amparado sólo en el criterio de la función de ser un transmisor de conocimientos?

\subsection{Discurso Profesional Docente}

Como se ha planteado la profesión docente no posee ni discurso propio ni autonomía profesional; depende del rol que le asigne el Estado. Entonces, el discurso especializado que utiliza la Profesión Docente pertenece a otras disciplinas, de las que la Profesión Docente obtiene su discurso "ajeno" que hace propio. Entre los discursos que se apropia la Profesión Docente, está el discurso de la Química, de la Medicina, de la Astronomía, entre otros.

Existe un tipo de discurso docente en un segundo sentido, referido al cómo enseñar. Tal discurso corresponde a otras disciplinas más específicas como son por ejemplo: la Psicología Educacional, la Sociología Educacional, la Antropología y la Etnografía. Estos discursos especializados aportan elementos específicos sobre "cómo enseñar" o sobre "cómo elaborar prácticas educativas" favorables a los sujetos y sus aprendizajes, desde enfoques centrados tanto en la situación didáctica de aula como en aspectos sociales, culturales y psicológicos de las instituciones educativas.

Como hemos venido sosteniendo, podemos plantear que la labor docente no puede focalizarse sólo en los discursos especializados que se involucran en la labor de aula, es decir, discursos especializados sobre qué y cómo enseñar. Debe ampliarse a consideraciones sobre los discursos de todas las funciones de la labor profesional docente, para lo cual seguiremos la propuesta planteada sobre las seis funciones de la labor docente surgidas de la revisión teórica del Estatuto Docente presentado anteriormente. A partir de ello, podemos aproximarnos a una definición inicial sobre qué entenderemos por Discurso Profesional Docente, la cual presentamos a continuación.

El Discurso Profesional Docente corresponde a los textos que produce y recepciona un(a) profesor(a) para el desempeño de su labor docente, 
referidos a cualquiera de las seis funciones consideradas como parte de la labor profesional de un(a) docente, ya sea en modalidad oral, escrita o multimodal; además, son parte también del Discurso Profesional Docente los textos especializados utilizados para la formación docente de especialidad vinculadas al qué enseñar y los textos de formación sobre las disciplinas que investigan y se especializan en cómo enseñar, y que se incluyen como investigaciones referidas a Educación.

Entre los textos considerados como Discurso Profesional Docente podemos considerar los decretos que contienen los contenidos curriculares de la enseñanza, el Estatuto Docente, las planificaciones, las evaluaciones, pruebas y/o exámenes, las clases, fichas, guías, libros de texto, libro de clases, documentos administrativos, libreta o registros de notas, reuniones de apoderados, documentos de orientación, test de indagación socioafectiva y vocacionales, fichas de seguimiento de casos de alumnos, entrevistas, documentos de investigación, reportes de derivación médica, psicológica, psicopedagógica entre otros.

\section{Conclusión}

Hemos revisado a partir del Discurso Profesional y de la Profesión Docente las características que deben considerarse para establecer la definición del Discurso Profesional Docente entre estas: el que no posea discurso propio y adquiera el de otras disciplinas que pueden estar ligadas o no a la educación; que no se centra en la mera transmisión de contenidos; que su legitimidad y rol social se las otorga el Estado a través de la regulación de sus contenidos especializados y de las funciones de la Profesión Docente.

También se ha señalado que las funciones investigativas desde la pedagogía apuntan específicamente a la función de aula y no consideran el resto de las funciones de la labor docente, lo que puede relacionarse con las actuales Reformas Educativas que buscan la eficacia y la eficiencia de los profesores. Esto último da cuenta del cambio de rol de la Profesión Docente con el Estado, transitando del rol vocacional o de apostolado, al rol de profesional.

La profesionalización docente puede ser entendida sólo con relación a una única función y se corre el riesgo de dejar las otras funciones profesionales de la labor docente y de la escuela en su conjunto.

Desde una perspectiva de la lingüística del uso, el Discurso Profesional Docente puede dar cuenta de las prácticas discursivas que surgen del 
desempeño de la labor docente, contribuyendo tanto desde los aspectos especializados como convencionales de los textos implicados en la Profesión Docente.

La Profesionalización de los docentes desde un enfoque lingüístico a partir del Discurso Profesional Docente puede aportar a la investigación y formación especializada requerida por los docentes en ejercicio y por sus formadores académicos, ya que daría cuenta de las funciones que forman parte de la labor docente, pero que en muchos casos no están incluidas en la formación que se entrega a los profesores.

Las próximas aportaciones sobre el Discurso Profesional Docente debieran ir en relación con una propuesta tipológica y luego a una propuesta de análisis que dé cuenta de la diversidad de textos involucrados en la Profesión Docente.

Es importante vincular, además, con mayor detalle, las relaciones de este concepto planteado con el discurso didáctico, el discurso instruccional y otros discursos no considerados en esta aproximación inicial.

\section{Referencias Bibliográficas}

Álvarez, M. (1997). Los textos comerciales. Madrid: Arco Libros.

Austin, J. (1996). ¿Cómo hacer cosas con palabras? Madrid: Paidós.

Bernstein, B. (1997). La estructura del discurso pedagógico. Vol. IV. Madrid: Morata.

Biblioteca del Congreso (1997). Estatuto Docente. Ley no 19.070 creada el 22.1.1997 y modificada el 17.11.1997.

Cabré, M. (2000). La terminología representación y comunicación. Barcelona: Universidad Pompeu Fabra.

Cabrera, J. (2003). "Discurso docente en el aula". Estudios Pedagógicos (29): 7-26. [en línea]. Disponible en: http:// scielo.cl/scielo.php?script=sci_arttext\&pid=S0718$07052003000100001 \& \operatorname{lng}=\mathrm{es} \& n r m=$ iso

Calvo,J. (2000). "Formación del profesorado desecundaria". EstudiosPedagógicos. (26): 107- 117. [en línea]. Disponible en: http:// scielo.cl/scielo.php?script=sci_arttext\&pid=S071807052000000100008\&lng=es\&nrm=iso

Cassany, D. (2004). "Explorando los discursos de las organizaciones". Foro hispánico: 49-60. 
Charaudeau, P. \& Maingueneau, D. (2005). Diccionario de análisis del discurso. Buenos Aires: Amorrurtu.

de Beaugrande, R. \& Dressler, W. (1997). Introducción a la lingüística del texto. Barcelona: Ariel.

de la Cruz, M.; Baudino, V.; Caino, G.; Ayastuy, R.; Ferrero, T.; Huarte, M.; Palacio, M.; Reising, A.; Scheuer, N.; \& Siracusa, P. (2000). "El análisis del discurso de profesores universitarios en la clase". Estudios Pedagógicos. (26): 9-23. [en línea]. Disponible en: http:// scielo.cl/scielo.php?script=sci_arttext\&pid=S0718$07052000000100001 \& \operatorname{lng}=\mathrm{es} \& \mathrm{nrm}=\mathrm{iso}$

; Schever, N.; Caíno, G; Huarte, M; Baudino, U; \& Ayastuy, R. (2001). "El discurso en clase de maestros de nivel primario en distintos sectores socioculturales. Estudios Pedagógicos. (27): 23- 41. [en línea]. Disponible en: http:// scielo.cl/scielo.php?script=sci_arttext\&pid=S0718$07052001000100002 \& \operatorname{lng}=$ es\&nrm=iso

Drew, P. \& Sorjonen, M. (2000). "Diálogo institucional” (pp. 141178). En. T. van Dijk (edit.) El discurso como interacción social Vol 2. Barcelona: Gedisa.

Freire, P. (1969). ¿Extensión o comunicación? Santiago de Chile: ICIRA. (1970). Pedagogía del oprimido. Buenos Aires: Siglo XXI. (1997). A la sombra de este árbol. Barcelona: El Roure.

Gamero, S. (2001). La traducción de textos técnicos. Barcelona: Ariel.

Giroux, H. (Edit.) (1990). "Los profesores como intelectuales". (pp. 171-178) Hacia una pedagogía crítica del aprendizaje. Barcelona: Piados/Mec [en línea]. Disponible en http://lie.upn. $\mathrm{mx} /$ docs/semopta/profesores.pdf

Gunnarson, B. (1998). "Academic discourse in changing context frames: the construction and development of a genre". En P. Evangelisti (Edit) Academic discourse in Europe. Roma: Bulzoni.

Ivanier, A.; Jaimovich, A.; Migliavacca, A.; Pasmanik, M.; \& Saforcada; F. (2004). ¿Qué regulan los estatutos docentes? Trabajadores de la educación, relaciones sociales y normativa. Buenos Aires: Ed. Instituto 
Movilizador de Fondos Cooperativos [en línea] http:// cculturalcoop.org.ar

Lerat, P. (1997). Las lenguas especializadas. Barcelona: Ariel.

Ley 19.070 Estatuto docente. Biblioteca del Congreso Nacional de Chile. [en línea]. Disponible en: http://subdere.gov.cl/1510/ articles-66514_recurso_1.pdf

López, C. (2002). "Aproximaciones al análisis de los discursos profesionales". Signos, 35 (51-52): 195-215. [en línea]. Disponible en: http://itesm.mx/va/FEV/ago03/cassany/lectura_lopez. pdf

Martínez, J. (2001). Arqueología del concepto "compromiso social" en el discurso pedagógico y la formación docente. Revista Electrónica de investigación educativa 3 (1) [en línea]. Disponible en http://redieuabc.mx/vol3n0l/ contenido-bonafe.html

Moirand, S. (1994)1. "Décire les discours de specialite", Lenguas para fines especificos, investigación y enseñanza. Alcalá de Henares: Universidad de Alcalá de Henares, 79-91.

Mumby, D. \& Clair, R. (2000). "El discurso en las organizaciones". (pp. 263296). En T. van Dijk (edit.) El discurso como interacción social Vol 2. Barcelona: Gedisa. 